\title{
Immersive Media and Books 2020: New Insights About Book Pirates, Libraries and Discovery, Millennials, and Cross-Media Engagement: Before and During COVID
}

\author{
Rachel Noorda ${ }^{1} \cdot$ Kathi Inman Berens ${ }^{1}$ \\ Published online: 4 May 2021 \\ ๑) Springer Science+Business Media, LLC, part of Springer Nature 2021
}

\begin{abstract}
Books exist within a connected media ecosystem, but few consumer behavior and experience studies capture the relationships between books and other media forms. In Immersive Media \& Books 2020, Drs. Rachel Noorda and Kathi Inman Berens from Portland State University explore crossmedia consumer behavior for books, video games, and TV/movies - capturing behaviors both before and during COVID19. The highlights of the report are highly distributed word-of-mouth discovery, the importance of author brand and genre, avid book engagement of Black and Latinx millennials, context-agnostic book discovery, cross-media engagement and discovery, multidimensional identities and behaviors of book pirates, multitasking as a feature of contemporary book consumption, and libraries as tools of discovery.
\end{abstract}

Keywords Avid book engagers · Crossmedia - Book piracy · Diverse readers · Nonwhite readers $\cdot$ Immersive media $\cdot$ Survey $\cdot$ TV $\cdot$ Movies $\cdot$ Games

\section{Introduction}

Immersive Media \& Books 2020 examines consumer behavior and engagement for books, video games, and TV/movies. It presents granular demographic data along three age groups (millennial, Gen X, and baby boomer), five U.S. regions (Midwest, Southwest, West, Northeast, Southeast), seven racial/ethnic groups (African American or Black; Asian American or Asian; European American or white; Hawaii Native or Pacific Islander; Latino, Latina or Latinx; Middle Eastern or North

Rachel Noorda

rnoorda@pdx.edu

Kathi Inman Berens

kberens@pdx.edu

1 Department of English, Portland State University, PO Box 751, Portland, OR 97207-0751, USA 
African; Native American, First Nations, or Native Alaskan), and gender. These findings are based on survey data collected in September and November 2020.

Immersive Media \& Books 2020 was published in February 2021 by Panorama Project, an organization centered on library research, and written by scholars at Portland State University, Drs. Rachel Noorda and Kathi Inman Berens. The two main goals of the study were to establish the place of books in the media ecosystem and understand the role of libraries in that ecosystem. This article summarizes the report's key findings.

\section{Terminology: Book Engagement and Immersion}

One of the key contributions of Immersive Media \& Books 2020 is its specific use of the terminology "book engagement", defined as "buying, borrowing, subscribing to, reading or gifting a printed book, an ebook, or audiobook in part or in whole." To capture the wide range of things people do with books, survey respondents were asked how many books they engaged per month, rather than how many books they read or bought. This was done in order to capture data beyond just avid readers or those who buy books. Book engagement includes a wide range of activities: checking out books from the library (and not necessarily reading them), giving books as gifts, discovering books via other media such as video games or films and TV, buying books but not reading them, buying books for purposes other than reading (collecting and displaying, for example), and buying books for school/work or hobbies. To gather data only about avid readers or book buyers would render invisible the many ways people engage with books. Capturing data beyond the "typical" reader or buyer as white female baby boomers who are reading or buying for entertainment gives a more accurate picture of the book engagement landscape in the United States in 2020. Who is engaging and what counts as engagement is a foundational piece of Immersive Media \& Books 2020.

Additionally, the report takes a wide approach to the term "immersive." Past discussions of book engagement have tended to claim book engagement as distinct from other media forms because of its immersive qualities, and the required dedication to deep, uninterrupted concentration. But Immersive Media \& Books 2020 shows that this is not true; books do not necessitate more concentrated or uninterrupted attention than other longform media like TV/movies and games. For example, the survey data shows that multitasking is a common feature of modern book engagement: $61 \%$ of ebook readers and $70 \%$ of audiobook listeners said that they were multitasking when engaging with these book forms. $53 \%$ of millennials report multitasking while reading printed books. Therefore, Immersive Media \& Books 2020 approaches "immersion" as a descriptor of the deep involvement people experience in the topic and/or storyworld. "Immersive" is a feature of longform storytelling, not a state of human attention. A person may engage an immersive world with full or partial attention. The data support a more nuanced view of how entertainment products and formats feed different types of attention. 


\section{Methods and Limitations}

Immersive Media \& Books 2020 utilizes a survey methodology to study consumer behavior and engagement. This information informs the report's analysis of how book buying, borrowing, discovery and consumption existed before the pandemic, and shifted during and because of it. The sample size for the survey was 4314, and the data was collected in September and November 2020. Respondents answered "yes" to a screening question about engaging with at least one book in the last twelve months. Because of this screening question, it is estimated that the survey captures the behaviors of at least $75 \%$ of Americans because, according to a 2019 Pew research study, $75 \%$ of Americans have read a book in the last year [10]. Immersive Media \& Books 2020 likely represents even more than $75 \%$ of the U.S. population because it captured the broader activity of book "engagement" rather than the narrower Pew research activity of "reading." The Immersive Media \& Books survey had a $95 \%$ confidence level, $1.5 \%$ margin of error, and $61.8 \%$ incident rate.

Quotas for age, race, gender, and region were enforced in the sample during collection to ensure that the survey was representative of and aligned with the most current U.S. Census data. The survey respondents proportionally match demographics of the U.S. bookselling regions (West, Southwest, Midwest, Northeast, Southeast), ages (millennials, Gen X, baby boomers), and racial/ethnic categories to match the U.S. Census.

The respondents were recruited through Qualtrics, and quotas were pushed starting with the harder-to-reach target groups, starting with non-white respondents, male respondents, and age quotas that were not filling as quickly. The length of the survey was approximately $15 \mathrm{~min}$ to encourage participation because research has found that the longer an online survey, the less likely respondents are to start and finish the survey [5]. The higher cost of administering a survey that takes longer than 15 min to complete was another constraint that limited the length of the survey. Constraint of time and survey space limited the number of questions asked. To minimize the risk of survey data reliance on self reporting (which can be subject to lying or misremembering), the questions were framed so that consumers don't have to give exact numbers, which can be difficult to remember, and the researchers worked in collaboration with Qualtrics to scrub the data for screening bad responses.

\section{Findings}

The highlights of Immersive Media \& Books 2020 are highly distributed word-ofmouth discovery, the importance of author brand and genre, avid book engagement of Black and Latinx millennials, context-agnostic book discovery, crossmedia engagement and discovery, multidimensional identities and behaviors of book pirates, multitasking as a feature of contemporary book consumption, and libraries as tools of discovery. 


\section{Highly Distributed Word-of-Mouth Discovery}

Respondents find books primarily via word-of-mouth recommendations from family, friends, and social media. When asked to select one top preferred method of book discovery, respondents most selected (1) recommendations from friends $20.8 \%$, (2) favorite author $15.3 \%$, (3) recommendations from family $12.1 \%$ and (4) recommendations on social media, such as Facebook, Instagram, Twitter, Reddit, YouTube, etc. $7.3 \%$. However, even word-of-mouth book discovery is highly distributed. Of the 20 choices that respondents could select for their preferred choice of book discovery, only 1/5th of respondents chose the top category: recommendations from friends. In other words, preference for book discovery methods is quite dispersed, indicating that there are many ways to reach audiences, dependent on more granular data about a book's target audience and niche. Further research is needed to understand more about how word-of-mouth is generated for book discovery. For example, people seem largely unaware of the role algorithms play in driving awareness either in opt-in spaces such as one's own curated social media feed, and in places where one can't opt out of algorithmic activity, such as in targeted ad placements inside e-commerce sites like Amazon.

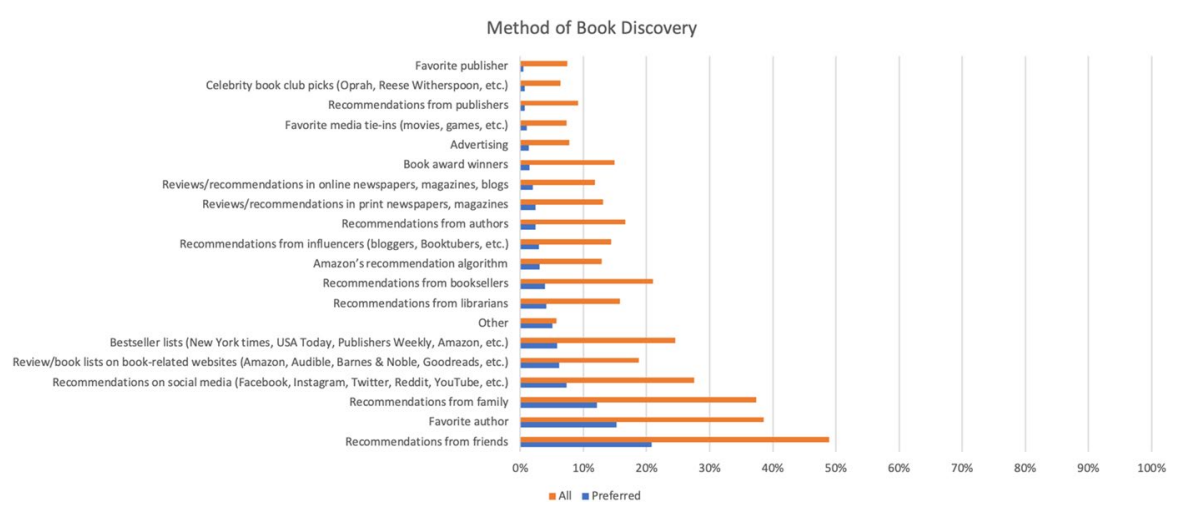

\section{The Importance of Author Brand and Genre}

Author brand recurs frequently in the data as an important factor in the how, where and why of book discovery and purchase. Favorite author is the \#2 preferred method of book discovery; in-person author events are the \#3 preferred place of book discovery. Author is the second-most important factor, after genre, motivating book purchase.

Certain subsections of the population rely on author brand for discovery more than others, particularly men, millennials, and Black and Latinx respondents. Men prefer in-person author events (15.8\%) and virtual author events $(6.1 \%)$ as places for discovery and rank author $27.2 \%$ for book purchase: these data all indicate higher 
degrees of author influence than is the case for women and the general survey population. Millennials discover books more via in-person author events $(20.2 \%)$ and virtual author events $(8.2 \%)$ than the general survey population. To a lesser extent than millennials but still greater than the general survey population, Gen X respondents also discover more through in-person (17.5\%) and virtual (7\%) author events. Black and Latinx respondents also had greater proportions finding books through inperson author events (20.6\% for Black and $17.5 \%$ for Latinx) than the general survey population.

Far and away, genre/category was the most important factor influencing book purchase $(39.8 \%$ of the general survey population). Surprisingly, price was a less important factor for book purchase than might be expected in the general population (9.2\%); but this datum doesn't capture the behavior of certain subgroups who don't purchase a book, such as book pirates and those who get books for free through book giveaways. For those people, price may well be the most important consideration.

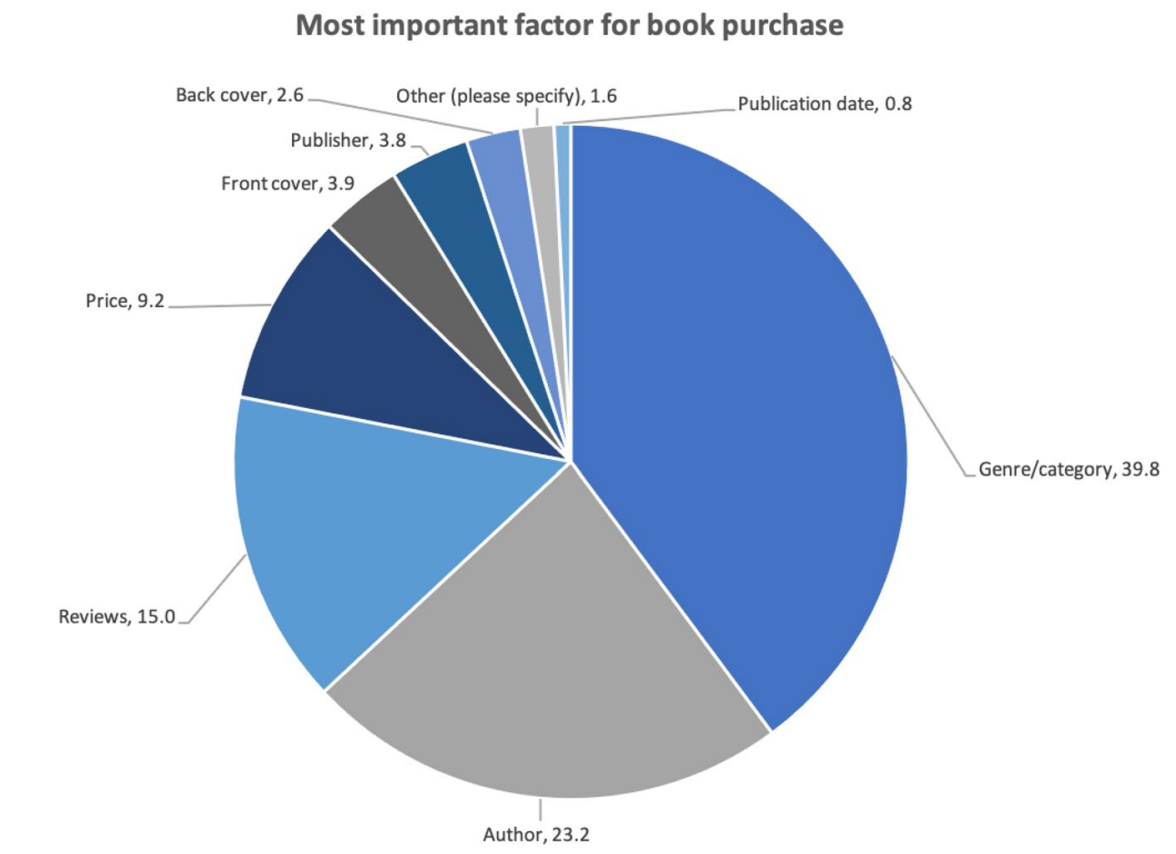

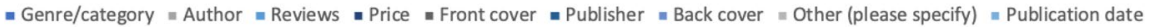

\section{Avid Book Engagement}

Immersive Media \& Books 2020 defines avid book engagers as respondents who "engaged" with 4 or more books per month (in any format: ebook, audiobook, or print book). These respondents account for $53 \%$ of the survey population. Avid book engagers are younger and more ethnically diverse than the general survey population, 
with greater percentages of Black or African American (16\% compared to $13 \%$ of the general survey population) and Latina/Latino/Latinx (14.4\% compared to $12.9 \%$ of the general survey population) respondents. $67 \%$ of Black or African American respondents are avid book engagers, and 59\% of Latina/Latino/Latinx respondents are avid book engagers. In comparison, only $50.1 \%$ of European American or white respondents are avid book engagers. Because Immersive Media \& Books 2020 captures book engagement behavior beyond typical definitions of reading and buying, it is able to reflect "domains of reading experience" [9], p. 697) and "variable literacies" [12], p. 50) that encompass various interactions with books across a range of book types/genres. Of respondents buying more books during COVID, again there are greater proportions of Black or African American (14\% compared to $13 \%$ of the general survey population) and Latina/Latino/Latinx (16.4\% compared to $12.9 \%$ of the general survey population) respondents than the general survey population.

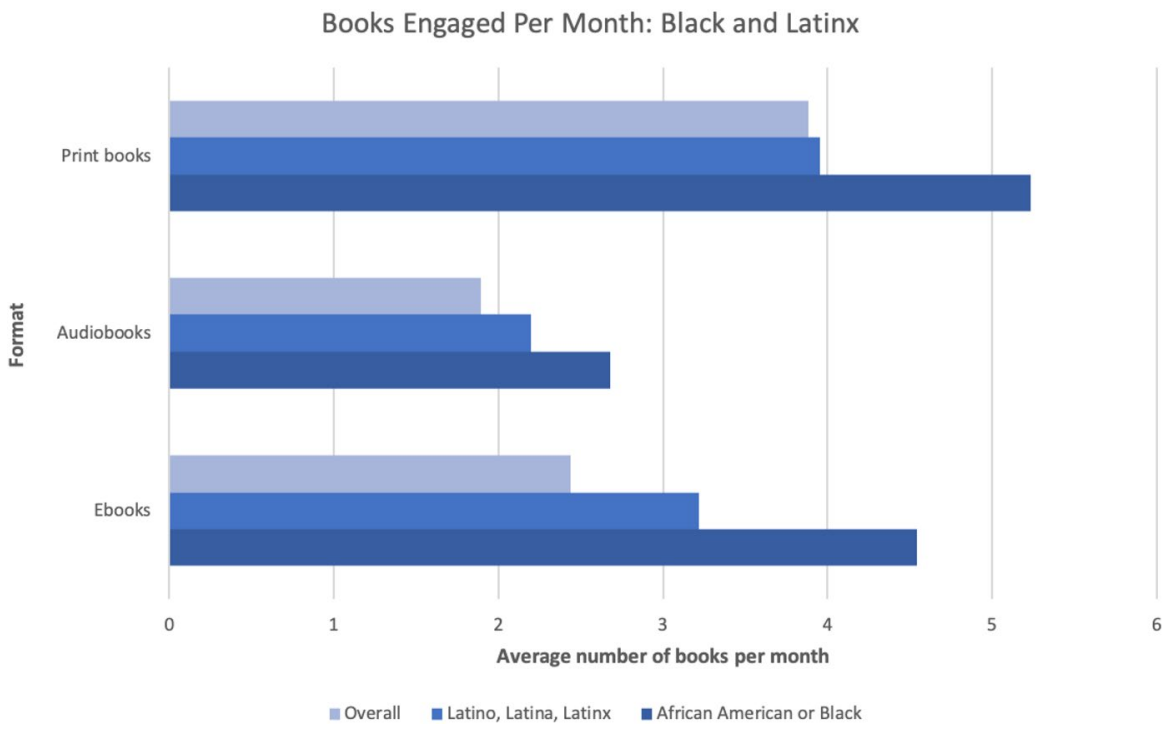

Across all formats, millennials engage with books more than either of their two older cohorts (Gen X and baby boomers). Millennials are also more ethnically diverse than other age categories. For example, millennial survey respondents were 24.4\% Black or African American and 25.4\% Latina/Latino/Latinx, both double the percentages for those racial categories in the general survey population. This trend of more ethnically diverse millennials is something that the U.S. population in general is experiencing, not just something that is happening in book and media consumption. White Americans are older than other racial groups in America (median age of 58) and census population projections suggest that over $50 \%$ of the U.S. population will be non-white by 2045 [14]. Therefore, there is an overlap in these demographics of age and race. Young ethnically diverse respondents (especially Black and Latinx millennials) are avidly reading, buying, borrowing, and subscribing to books. The 
book industry has long underestimated Black, Latinx and millennial book engagers as desirable target audiences. These are consumers to watch going forward.

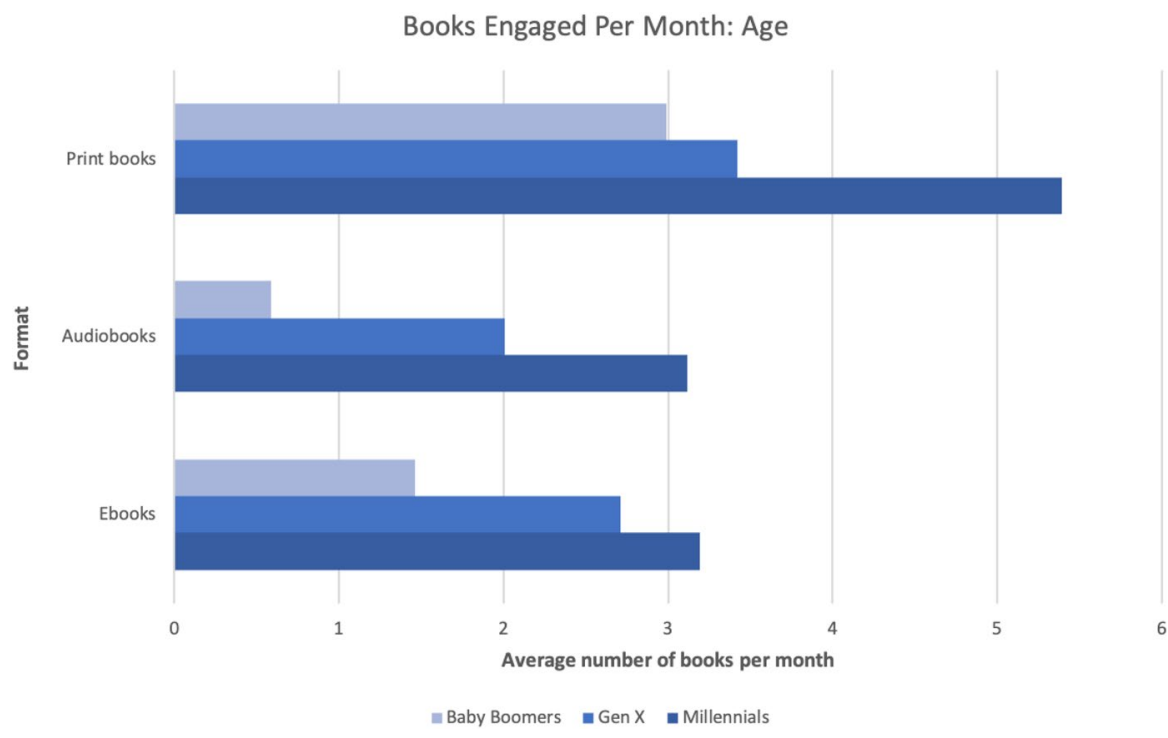

The majority of Americans did not change book buying habits during COVID but book sales shot up by $8.2 \%$, the largest surge in a decade, according to NPD BookScan, the largest book sales tracking information in the U.S. Most survey respondents reported that their book buying stayed the same during COVID: $62.1 \%$ said their ebook buying stayed the same during COVID, 67.1\% said their audiobook buying stayed the same during COVID, and 57\% said their print buying stayed the same during COVID. This means that the $8.2 \%$ sales surge was driven by an avid but smaller group of engagers. The report's data suggest one possibility is that avid books engagers $(4+$ books per month) drove the increase in book sales during 2020. 


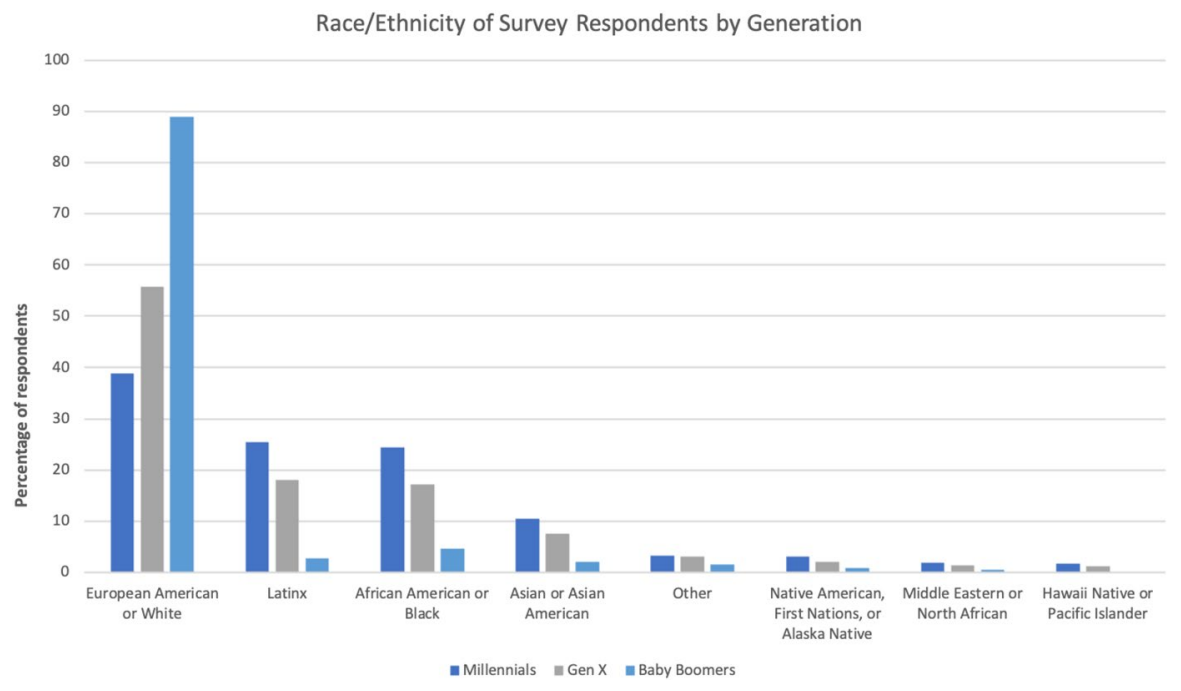

\section{Context-Agnostic Book Discovery}

Another major finding of the report is that book discovery is context-agnostic; that is, consumers are discovering books in one setting (online vendor, brick-andmortar bookstore) and then buying it in another. Context-agnostic discovery is especially true for millennials.

For the general survey population, the following discovery contexts led to other places of book buying: $35.9 \%$ of respondents bought a book online that they first found in a library. $31.1 \%$ of respondents bought a book in a bookstore that they first found in a library. $44.5 \%$ of respondents bought a book in a bookstore that they first found online. $43.9 \%$ of respondents bought a book online that they first found in a bookstore. $44.5 \%$ of respondents borrowed a book from the library that they first found online.

For millennials, context-agnostic book discovery is even more pronounced. $60.7 \%$ of respondents bought a book at a bookstore that they first found online; slightly fewer (59.3\%) bought a book online that they found in a bookstore. Discovery at a library led to a purchase online $(50.9 \%)$ or in a bookstore $(47.9 \%)$. Millennials are more likely to borrow a book in a library that they first found online $(52.7 \%$, compared to $44.5 \%$ in the general survey population). All roads lead back to the fact that millennials consume more books across formats than other age groups, even among avid book engagers of other generations. 


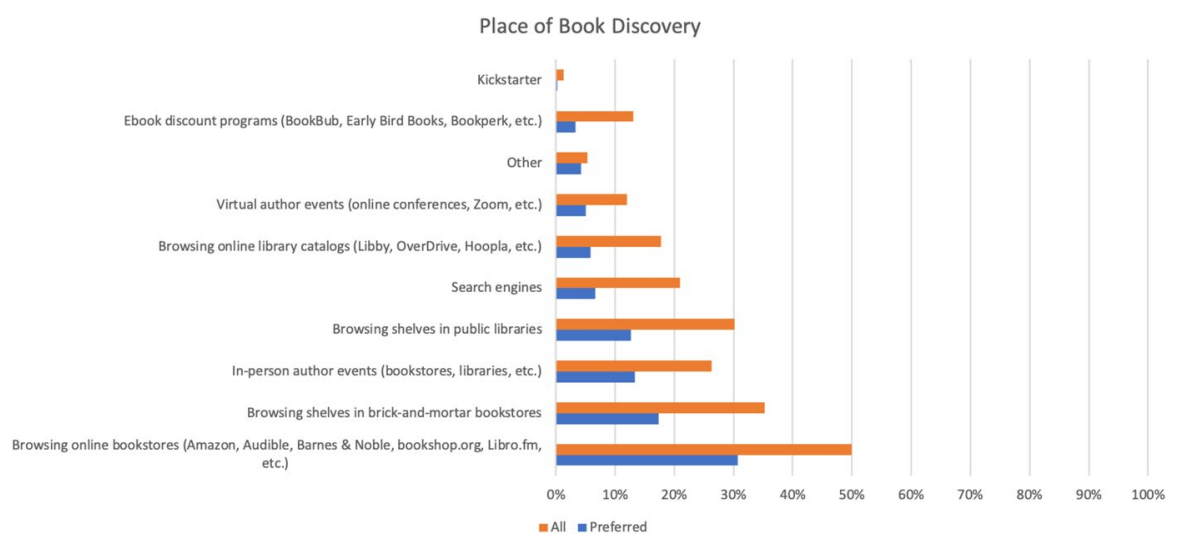

The top four preferred places that respondents discover books are (1) browsing online bookstores (Amazon, Audible, Barnes \& Noble, bookshop.org, Libro.fm, etc.) $30.7 \%$, (2) browsing brick-and-mortar bookstores $17.4 \%$, (3) in-person author events (bookstores, libraries, etc.) $13.3 \%$, and (4) browsing shelves in public libraries $12.7 \%$. These preferences highlight the importance of browsing and in-person options to discovery. Comparatively, only $5 \%$ of respondents preferred virtual author events and only $6.7 \%$ discovered books through search engines. It is worth noting, that attitudes toward virtual events might have shifted to become more positive since the time of data collection (September and November 2020) as people have become more acclimated to attending virtual events. This datum captures just one of many behaviors that might be permanently changed by COVID-era habits.

\section{Cross-Media Engagement and Discovery}

Books exist within an interconnected media ecosystem. One of the main aims of this study and report was to position book engagement beside engagement with other longform content in games and TV/movies. Cross-media discovery (discovering books through video games or TV/movies and vice versa) is high amongst survey respondents, suggesting that audiences are already accustomed to traversing media to pursue stories and worlds they enjoy; there is likely more opportunity for cross-media collaboration. $60.3 \%$ of respondents discover $\mathrm{TV} /$ movies or games through books and $61.2 \%$ discover books or games through TV/movies. Cross-media discovery is lowest from games: $33.1 \%$ discover books or $\mathrm{TV} / \mathrm{mov}-$ ies through games. Cross-media discovery varies across age categories: crossmedia discovery is highest with millennials and lowest with baby boomers. For example, $72.4 \%$ of millennials discover TV/movies and games through books, $72.9 \%$ of millennials discover books or games through TV/movies, and $48.1 \%$ of millennials discover books or TV/movies through games. 
Respondents engage across media. Between their average engagement before and during COVID, respondents had 3.5\% growth in those "very" engaged with books, $8.5 \%$ growth in those "very" engaged in TV/movies, $4.4 \%$ growth in those "very" engaged in PC and console games, and 5.3\% growth in those "very" engaged with phone and tablet games. This growth is even higher for avid book engagers, who are even more active across media. Between their average engagement before and during COVID, avid book engagers had 5.3\% growth in those "very" engaged with books, $8.7 \%$ growth in those "very" engaged in TV/movies, 5.3\% growth in those "very" engaged with PC and console games, and 5.9\% growth in those "very" engaged with phone and tablet games.

Piracy is a cross-media problem. $11.4 \%$ of respondents pirate games, $14.4 \%$ of respondents pirate books, and $19.3 \%$ of respondents pirate TV/movies. Adjacent media industries might learn best strategies and practices from each other. The music industry was the first entertainment industry in the digital age to experience revenue loss due to peer-to-peer trading of mp3s. Musicians have adapted to the reality of piracy by putting more of a premium on things that are harder to pirate, such as fan merchandise and live concerts. The public's demand for printed books suggests that authors won't have to shift their revenue streams as extremely as did musicians. But publishers will have to make the value proposition of buying a printed book more evident to younger people habituated to leasing access to entertainment.

\section{Book Pirates: Multidimensional Identities and Behaviors}

Book pirates are not only thieves but also customers, library patrons, fanfiction readers/writers, and more. Compared to the general survey population, a higher percentage of book pirates during COVID are buying more ebooks (38.7\%), audiobooks $(27.1 \%)$ and print books $(33.7 \%)$; a higher percentage of book pirates are also borrowing more ebooks $(30.1 \%)$, audiobooks $(31.6 \%)$, and print books $(28.5 \%)$. Pirates are slightly more likely than the general population to own library cards $(77.2 \%$ compared to $75.8 \%$ of the general survey population). Book pirates are younger; greater percentages of them are men and BIPOC people than the general survey population. The data show that book pirates are avid readers who will buy books when the value proposition is clear to them; for example, pirates are much more likely than the general survey population to buy books in multiple formats (41.5\%). As book pirates are also avid book engagers and readers, they are invested in storyworlds. This is evident in their engagement with fanfiction. While only $12.2 \%$ of the general survey population ( $5.8 \%$ of responses to the question) are reading/downloading fanfiction, the percentage was much higher for book pirates: $27.4 \%$. Book pirates are more than twice as likely than the general population to write and read fanfiction. Their passion for extending storyworlds is an opportunity for those who can get to know these consumers. Thus, book pirates have multidimensional identities; they are not only pirates but also readers, borrowers, and buyers. This disrupts the usual absolute perspective - pirate or not pirate-with a more nuanced understanding and spectrum of piracy behavior. 


\section{Buying Books: Book Pirates vs Overall}

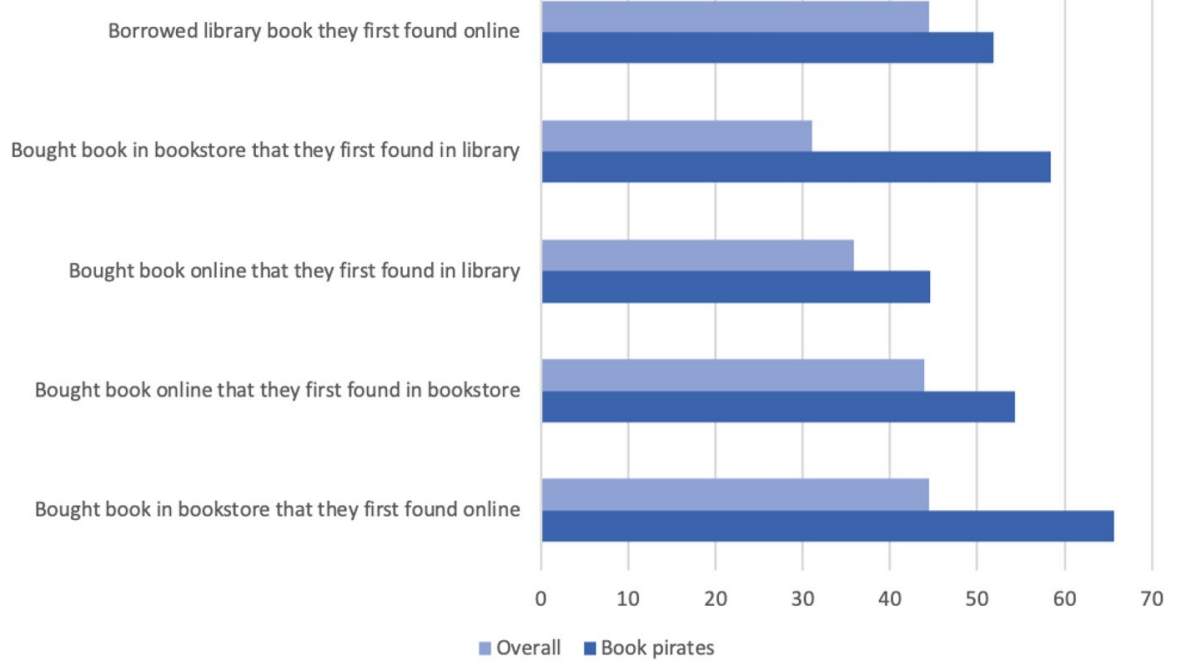

\section{Libraries as Tools of Discovery}

The role of libraries in the media ecosystem has been called into question in the last few years, particularly following Macmillan's ebook embargo to libraries on new titles because "free" library borrowing was seen to be cannibalizing sales and "decreasing the perceived economic value of the book" [1]. The Macmillan ebook embargo was lifted in March 2020 [2] but the debate about libraries has continued.

The most important finding is that library borrowing encourages book sales. Immersive Media \& Books 2020 finds that libraries, bookstores, and online channels mutually reinforce each other, leading to engagement and sales in other channels. Approximately 1/3rd of respondents bought a book online that they first found in a library (35.9\%) and similarly 1/3rd of respondents bought a book in a bookstore that they had first found in a library $(31.1 \%)$, demonstrating that library discovery is leading to book purchase in these cases.

In Immersive Media \& Books 2020, 75.8\% of respondents are library card holders. Older generations such as baby boomers have higher proportions of library card holders $(76.4 \%)$ than younger generations like millennials $(70.5 \%)$. The report found that library borrowing does not preclude or discourage respondents from buying books; on the contrary, a greater percentage of library card holders said they were buying more books during COVID than the general survey population, in every format. 
When a book is unavailable at the library, our data reveal that the most likely thing a patron will do is put themselves on the hold list. After that, the two most likely things people do when a book is unavailable from the library in the format they want is buy it online (23.2\% of respondents) or buy it from a local bookstore (18.3\% of respondents). Library unavailability leads some respondents to go elsewhere and purchase the book rather than wait. More discovery is needed to investigate the "long tail" of author discovery at libraries. Do patrons choose other books by an author when the one they want isn't available? Libraries de-risk sampling books outside one's favorite genre. How often does this lead to discovery of a new author or genre? Further study could yield insight about how libraries foster curiosity, and the extent to which that curiosity drives book engagement.

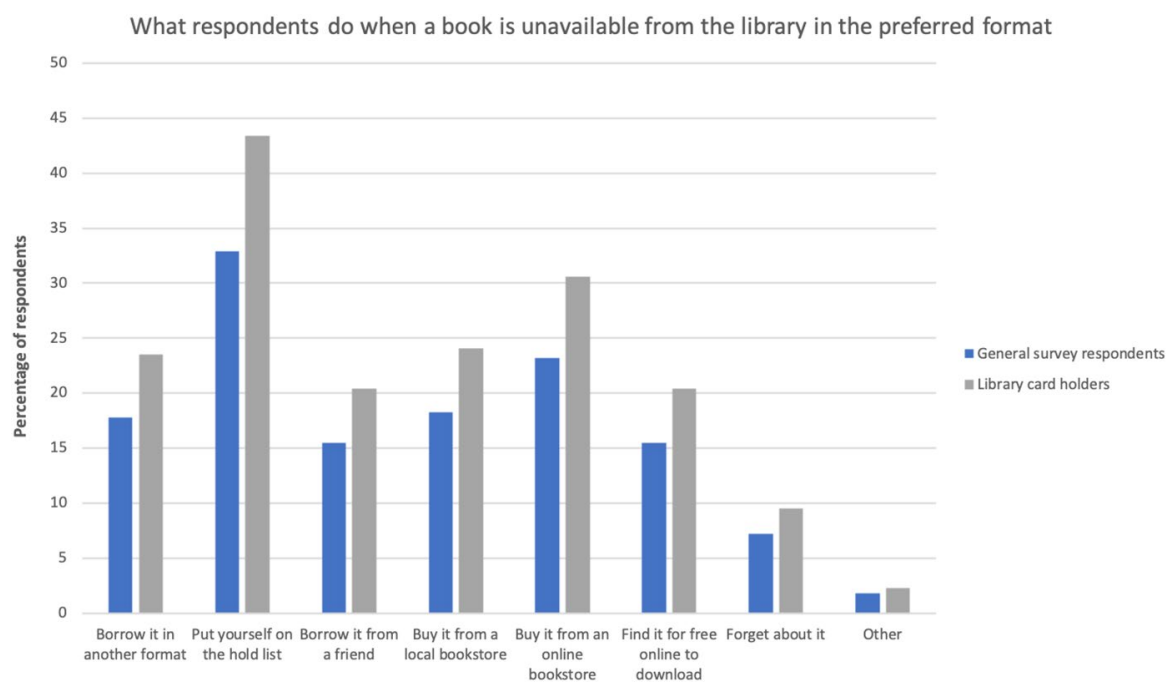

\section{Conclusion}

By taking a broad definition to book engagement as "buying, borrowing, subscribing to, reading or gifting a printed book, an ebook, or audiobook in part or in whole", Immersive Media \& Books 2020 captures a wider and more inclusive range of book engagement behavior. Additionally, these book engagement behaviors are juxtaposed with other media engagement behaviors for TV/film and games since media exist in a networked ecosystem as experienced by the consumer.

The major findings of the report include highly distributed word-of-mouth discovery, the importance of author brand and genre, avid book engagement of Black and Latinx millennials, context-agnostic book discovery, cross-media engagement and discovery, book pirates as customers in certain circumstances, and libraries as tools of discovery. Book discovery preference is for word-of-mouth recommendation methods, but even that is highly distributed and thus depends on a book's particular 
audience and niche. Author brand is important to the where, how, and why of book discovery as is the book's genre, which is the \#1 most important factor driving book purchase. Black and Latinx millennial book engagement exceeds previous industry benchmarks and expectations for these groups, which indicates that the industry has fallen far short of discovering the reading habits and preferences of this important audience. Avid book engagers are avid across media, not just books but also TV/ film and games. The identities and behaviors of book pirates are shown in the report to be more nuanced than is often portrayed in industry and academic discussions of piracy. Book pirates are also consumers, library patrons, fanfiction readers, and avid readers. Context-agnostic book discovery indicates that consumers find a book in one place and then buy it in another place, with a networked ecosystem of libraries and bookstores working together both online and brick-and-mortar. Relatedly, libraries serve as tools of discovery, where library card holders are more inclined to be avid book buyers, and where library patrons are most likely to purchase a book if it is unavailable from their local library in the preferred format.

Immersive Media \& Books 2020 is the first in an intended annual study to assess longitudinal data and consumer behavior about books, TV/film, and games.

\section{References}

1. Albanese, A. After Tor Experiment, Macmillan Expands Embargo on Library E-books. Publishers Weekly. Jul 25, 2019. https://www.publishersweekly.com/pw/by-topic/industry-news/libraries/artic le/80758-after-tor-experiment-macmillan-expands-embargo-on-library-e-books.html

2. Albanese, A. Macmillan Abandons Library Ebook Embargo. Publishers Weekly. 17 March 2020. https://www.publishersweekly.com/pw/by-topic/industry-news/libraries/article/82715-macmillanabandons-library-e-book-embargo.html

3. Frey, W. Now More Than Half of Americans Are Millennials or Younger. The Brookings Institution. July 30, 2020. https://www.brookings.edu/blog/theavenue/2020/07/30/now-more-than-half-ofamericans-are-millennials-or-younger/

4. Dimock, M. Defining Generations: Where Millennials end and Generation Z begins. 17 January 2019. https://www.pewresearch.org/fact-tank/2019/01/17/wheremillennials-end-and-gener ation-z-begins/

5. Galesic M, Michael B. Effects of questionnaire length on participation and indicators of response quality in a web survey. Public Opin Q. 2009;73(2):349-60.

6. Guren, C, Thad M, and Steven S. COVID-19 and Book Publishing: Impacts and Insights for 2021. Publishing Research Quarterly (2021): 1-14.

7. Maher, J. Covid-19 Impact Listing: Cancellations, Closings, Policy Changes, and More. Publishers Weekly. https://www.publishersweekly.com/pw/by-topic/industrynews/trade-shows-events/article/ 82672-covid-19-ongoing-list-of-cancellations.html.

8. Milliot, J. A Surprisingly Strong Year of Book Sales Continues. Publishers Weekly. Oct 9, 2020. https://www.publishersweekly.com/pw/by-topic/industrynews/bookselling/article/84593-a-surpr isingly-strong-year-of-book-sales-continues.html.

9. Nishikawa K. Merely Reading. PMLA. 2015;130(3):697-703.

10. Perrin, A. Who Doesn't Read Books in America? Pew Research Center. Sep 26, 2019. https://www. pewresearch.org/fact-tank/2019/09/26/who-doesnt-read-books-inamerica/

11. Price, G. U.S. Print Book Sales Rose 8.2 Percent in 2020 According to Data From NPD. 7 January 2021. https://www.infodocket.com/2021/01/07/u-s-print-book-sales-rose-8-2-percent-in-2020-accor ding-to-data-from-npd/

12. Radway, J. Interpretive communities and variable literacies: The functions of romance reading. Daedalus (1984): 49-73. 
13. Rea, A. Reading Through the Ages: Generational Reading Study. Library Journal. Jan 6, 2020. https://www.libraryjournal.com/?detailStory=Reading-Through-the-Ages-Generational-Readi ng-Survey.

14. Schaeffer, K. The Most common age among whites in the U.S. is $58-$ more than double that of racial and ethnic minorities, July 30, 2019, https://www.pewresearch.org/fact-tank/2019/07/30/ most-common-age-among-usracial-ethnic-groups/.

Publisher's Note Springer Nature remains neutral with regard to jurisdictional claims in published maps and institutional affiliations. 